\title{
EXPERIÊNCIA E IDEAIS DE VIDA RELIGIOSA EM MOSTEIROS PORTUGUESES CLARIANOS, NOS SÉCULOS XVII E XVIII'
}

\author{
Lígia Bellini \\ Universidade Federal da Bahia. \\ Moreno Laborda Pacheco \\ Universidade Federal da Bahia.
}

\section{Resumo}

Este artigo analisa ideais de prática religiosa, perfis humanos e vivências que emergem de escritos versando sobre vida monástica feminina do ramo clariano em Portugal, nos séculos XVII e XVIII. O quadro de comportamentos tidos como exemplares pelas religiosas, nas crônicas conventuais e nos textos de aconselhamento, é aqui comparado com as prescrições constantes nos regulamentos, concebidos sob o controle da instituição eclesiástica. Considera-se que as diferenças entre os modelos criados pelas monjas e o mais institucional da Igreja expressam as formas particulares de apropriação, por estas, das regras a que estavam submetidas.

\section{Pallavras-chaves}

Modelos de vida religiosa $\bullet$ experiência conventual feminina $\bullet$ Portugal nos séculos XVII e XVIII.

\section{Abstract}

This article is concerned with models of religious practice, human profiles and experience that emerge from writings on Franciscan women's monastic life in seventeenth and eighteenth-century Portugal. The behaviour regarded as exemplary by the cloistered women, in chronicles of monasteries and in counselling texts addressed to the sisters, is compared with prescriptions from the rules conceived under Church control. We consider that the differences between the models created by the nuns and the more institutional paradigm that is found in Church regulations express the particular forms of interpretation, by the sisters, of the rules to which they were submitted.

\section{Keywords}

Models of religious life $\bullet$ women's experience in convents $\bullet$ Seventeenth and eighteenth-century Portugal.

\footnotetext{
${ }^{1} \mathrm{O}$ presente artigo foi escrito com base em investigação que recebeu apoio financeiro do $\mathrm{CNPq}$, com bolsa de produtividade em pesquisa.
} 
Em seu estudo sobre a produção poética conventual feminina em Portugal, no Antigo Regime, Isabel Morujão denomina os textos por ela investigados de "espelhos do ser. Espelhos de tinta" que projetam experiências e formas de perceber o mundo, os homens, a divindade, o sagrado e o profano. ${ }^{2} \mathrm{O}$ presente artigo explora outros gêneros de literatura conventual portuguesa, versando sobre vida monástica feminina do ramo clariano no período, com o objetivo homólogo de buscar compreender ideais de prática religiosa, perfis humanos e vivências que deles emergem. Entre os textos estudados, encontram-se três crônicas conventuais escritas por monjas. Duas delas, manuscritas, foram compostas na primeira metade do século XVII, por religiosas afiliadas à Primeira regra de santa Clara - o Tratado da coriosa fundação do Convento de IESV de Setuval, da madre Leonor de São João (que teve sua primeira versão acabada em 1630, mas que inclui registros até 1646), ${ }^{3}$ e a Noticia da fundação do Convento da Madre de Deos das religiozas descalças de Lisboa, atribuída a Maria do Sacramento (produzida entre 1639 e 1652). ${ }^{4}$ A terceira, intitulada Jardim do ceo, plantado no Convento de Nossa Senhora da Conceição da cidade de Braga, de autoria da madre Maria Benta do Ceo (publicada em 1766), ${ }^{5}$ trata da trajetória de uma comunidade de concepcionistas, de 1629 até 1764 . A Ordem da Conceição, criada em Toledo em 1489, conquanto tenha tido diferentes regras no decorrer da sua existência, seguiu predominantemente orientação clariana, em especial a chamada Segunda regra. ${ }^{6}$

\footnotetext{
${ }^{2}$ MORUJÃO, Isabel. Por trás da grade: Poesia conventual feminina em Portugal (séculos XVII - XVIII). Tese de doutorado. Porto: Universidade do Porto, 2005, p. 634.

${ }^{3}$ SÃO JOÃO, Leonor de. Tratado da antiga e coriosa fundação do convento de IESU de Setúbal. Setúbal, 1630, [MS].

${ }^{4}$ SACRAMENTO, Maria do. Notícia da fundação do Convento da Madre de Deus das religiosas descalças de Lisboa [...]. Lisboa: s/e, 1639, [MS]. Diogo Barbosa Machado, na compilação de autores portugueses que produziu no século XVIII, aponta Maria do Sacramento, que habitou a casa entre 1623 e 1679, como autora da obra. Estudo mais recente, feito por Ivo Carneiro de Souza, propõe que a Noticia tem autoria tripla, de Catarina das Chagas, Joanna da Piedade e Margarida da Trindade. MACHADO, Diogo Barbosa. Biblioteca lusitana histórica, crítica e cronológica. $2^{\mathrm{a}}$ ed. Lisboa: Academia Real da História Portuguesa, 1930-1934, 4 vols., tomo 3, p. 423; SOUZA, Ivo Carneiro de. Rainha d. Leonor (1458-1525). Poder, misericórdia, religiosidade e espiritualidade no Portugal do Renascimento. Lisboa: Calouste Gulbenkian, 2002, p. 499-500.

${ }^{5}$ CEO, Maria Benta do. Jardim do ceo, plantado no Convento de Nossa Senhora da Conceição da cidade de Braga [...]. Lisboa: Officina de Manoel Coelho Amado, 1766.

${ }^{6}$ A designação Primeira regra de santa Clara refere-se à regra escrita por esta e aprovada pelo papa Inocêncio IV em 1253, embora a ordem tenha sido governada por outros regulamentos, anteriores a este, desde 1211. A promulgada pelo papa Urbano IV, em 1263, é conhecida como a Segunda regra. A Primeira regra, adotada com certas adaptações quando das reformas de santa
} 
Ao lado de relatos sobre a fundação das respectivas casas monásticas e sobre episódios de suas histórias, as crônicas trazem informações sobre a vida de religiosas que as teriam habitado. São, em geral, pequenas biografias que não seguem um padrão determinado no que diz respeito ao escopo e organização das informações que apresentam. Algumas tratam com detalhe de aspectos relativos às suas personalidades, à sua origem, à extração de sua família, a seu comportamento dentro do claustro, a manifestações de virtude e santidade e a como se deu a sua morte, entre outros. Em grande parte das vezes, no entanto, as irmãs são citadas apenas circunstancialmente, figurando seu nome, um fato ou uma data a ele relacionados.

Uma das partes que compõem o tratado sobre o convento de Setúbal é dedicada às biografias de 114 religiosas que lá “entraraõ, viveraõ, e morreraõ com notável exemplo". ${ }^{7}$ Outra seção constrói a memória dos abadessados exercidos na casa, de 1581 em diante. Além das monjas centralmente contempladas nestes relatos, há menção a outras 63 professas na casa. Sem um espaço reservado especialmente para elas, seus nomes aparecem aqui e acolá, em registros sobre ocasiões especiais ou como coadjuvantes em narrativas sobre outras freiras mais importantes. Na Noticia, redigida na forma de diálogos que, pelo que consta na sua introdução, teriam ocorrido em reuniões conhecidas como "fogueiras", que tiveram lugar no natal de 1638 , são ao todo 86 religiosas citadas. No Jardim do ceo, 75 sórores são mencionadas, quase três quartos delas apenas de passagem. A maior parte do livro consiste no relato sobre as vidas de vinte freiras do convento (uma delas ingressada no Mosteiro das Capuchas Descalças da Vila de Chaves), com cada capítulo dedicado a uma religiosa.

Estas memórias de conventos, que fazem referência a um considerável número de irmãs (num total de pouco menos de trezentas e cinquenta), permitem um tratamento quantitativo, com vistas à investigação de desde o

Colette de Córbia e de Maria Lorenza Longo, esta última fundadora das Clarissas Capuchinhas, expressa mais fielmente o espírito franciscano inicial, enfatizando a renúncia aos bens materiais pessoais e a limitação dos bens do convento ao estritamente necessário para a sobrevivência. Uma análise dos diferentes ramos e reformas da ordem e de aspectos de suas constituições encontrase em SENSI, Mario. Clarisses: entre spirituels et observants. In: Sainte Claire D’Assise et sa postérité - Actes du Colloque International organisé à l'occasion du VIII ${ }^{\mathrm{e}}$ Centenaire de la naissance de sainte Claire. Paris: Comité du VIII ${ }^{\mathrm{e}}$ Centenaire de sainte Claire, 1995, p. 101-118. Ver também DHONT, René-Charles. Clare among her sisters. Youngstown, Ohio: Catholic Publishing Company, 1987, p. 157-160 e Província dos Capuchinhos de São Paulo - Fontes, disponível em http://www.procasp.org.br (acessado 20 janeiro 2008).

${ }^{7}$ SÃO JOÃO. Tratado [...], op. cit., fl. 2v. 
perfil socioeconômico até diversos elementos das trajetórias de vida, formas de espiritualidade, hábitos cotidianos, entre outros. Para fins de uma análise serial do perfil das ingressadas nos conventos, foram registradas as informações disponíveis sobre todas as mencionadas, mesmo que sobre muitas delas só figurem um ou outro detalhe. O número de 86 religiosas citadas na Noticia inclui as personagens que participam dos diálogos ao longo da narrativa. É impossível verificar se estas personagens se baseiam em monjas que realmente habitaram o convento e participaram das "fogueiras" do ano de 1638 e de outros encontros edificantes nos anos posteriores, mas, de todo modo, elas foram incluídas na série construída. Decerto que adotar cegamente a ideia de que "Alexandra", "Macrina", "Luduvina", "Abadeça" e "Noviça" são nomes fictícios para pessoas reais, como a introdução do tratado quer nos fazer crer, ${ }^{8}$ é ignorar a capacidade da narrativa de criar um efeito de verdade para o texto. Contudo, o potencial dessas personagens/freiras de revelar as atitudes e costumes esperados na vida consagrada feminina é o mesmo se comparado às descrições de mulheres "reais". A inclusão, na série, de informações sobre todas as religiosas mencionadas permitiu constituir uma amostragem que não leva em conta apenas as figuras de maior destaque nas casas.

As biografias e relatos de acontecimentos que se encontram nas crônicas não são aqui necessariamente considerados como fontes para o estudo de indivíduos, comportamentos e episódios que teriam de fato ocorrido, e sim como indícios de hábitos e atitudes tidos como exemplares pelas irmãs. Ideais de vida religiosa existentes entre as monjas também emergem de outros gêneros de escrita - dos textos de aconselhamento espiritual, como o Ramalhete de flores espirituaes, de Maria Madalena do Sepulcro; ${ }^{9}$ dos voltados para a descrição das rotinas monásticas, como a segunda parte do tratado sobre o Convento de Setúbal; assim como de um longo poema, intitulado Colloquios com Christo crucificado, de Cecilia do Espirito Santo. ${ }^{10}$ Estes são comparados com as prescrições constantes nos regulamentos, concebidos sob o controle da instituição

\footnotetext{
8 "Naõ se poem os proprios nomes das religiozas por parecer inconveniente por alguas rezões". SACRAMENTO. Notícia [...], op. cit., fl. 3.

${ }^{9}$ SEPULCRO, Maria Madalena do. Ramalhete de flores espirituaes, colhidas do Jardim Serafico, da doutrina de varios padres capuchinhos, para uso das amadas noviças, \& professas da Primeira regra de nossa madre santa Clara [...]. Lisboa: Bernardo da Costa, 1700.

${ }^{10}$ ESPIRITO SANTO, Cecilia do. Colloquios com Christo crucificado de hum peccador arrependido. Lisboa: Officina de Miguel Manescal, 1688.
} 
eclesiástica, e também com determinações que se encontram nos comentários às regras. Considera-se que as diferenças entre os modelos criados pelas religiosas e o mais institucional da Igreja expressam as formas particulares de apropriação, por elas, das regras a que estavam submetidas.

Os textos escritos por religiosas parecem dirigir-se prioritariamente às suas próprias companheiras nos conventos. Cumprir uma função pedagógica e de exemplaridade é um dos objetivos predominantes da literatura conventual feminina no Portugal da época. ${ }^{11}$ No entanto, há indícios, nas obras, de que ao menos parte de suas autoras tinha em mente um público mais amplo. O tratado sobre a fundação do convento de Setúbal, a despeito de ter sido divulgado e de ter chegado até nós como manuscrito, obteve licença das autoridades competentes para ganhar a forma de impresso. O Jardim do ceo teve uma edição impressa de boa qualidade, contando para isto com o patrocínio de membros do clero católico que se manifesta na dedicatória, na apresentação e nas licenças para publicação. No final do livro, sua autora afirma: "parece-nos bem suspender a penna, e sujeitar humildemente naõ só á correcção da santa Madre Igreja quanto havemos dito, senaõ tambem a todo o Varaõ douto, que dasapaixonado o ler $[\ldots . .]^{\prime 2}{ }^{12}$ Além disso, o qualificador do Santo Ofício que assina a autorização para publicação faz referência às "religiosas dos mais mosteiros", que poderiam beneficiar-se com os exemplos de virtude contidos na obra. Também foram publicados o Ramalhete de flores espirituaes e os Colloquios com Christo crucificado. Verifica-se, nestas três últimas obras, a importância das dedicatórias a figuras ilustres, do universo civil ou eclesiástico, para sua publicação e circulação. ${ }^{13}$ Cecilia do Espírito Santo traduz este mecanismo no pedido, dirigido ao frei Jeronymo de Jesus, a quem a obra é dedicada, de que seu patrocínio lhe "dê azas com que voe felizmente pelo mundo". ${ }^{14}$

Quer se dirigissem mais para um uso interno, quer fossem voltados para leitores fora dos claustros femininos, de forma geral esses escritos, conforme foi apontado anteriormente, parecem ter mais compromisso com a criação de uma imagem modelar da atuação das religiosas do que com a representação

\footnotetext{
${ }^{11}$ MORUJÃO. Por trás da grade, op. cit., p. 113.

${ }^{12}$ CEO. Jardim do ceo [...], op. cit., p. 189.

${ }^{13}$ Ver, a este respeito, MORUJÃO, Isabel. Entre o convento e a corte: algumas reflexões em torno da obra poética de sóror Tomásia Caetana de Santa Maria. Revista da Faculdade de Letras - Línguas e Literaturas, Porto, anexo V, 1993, p. 123-141, p. 126-127.

${ }^{14}$ ESPIRITO SANTO. Colloquios [...], op. cit., Dedicatória.
} 
da realidade vivida nos mosteiros. Quando lidos pelas ingressadas nas casas monásticas, cumpriam o papel de forjar os modelos que serviriam de guia para a espiritualidade ali mantida. Mas também expressam a preocupação das autoras em ressaltar, para instituições, grupos e indivíduos fora dos conventos, o valor da comunidade religiosa, através do enaltecimento das monjas que dela faziam parte.

No caso específico das crônicas, em se tratando de uma literatura voltada para a apresentação de casos exemplares, a presença de caracterizações negativas é quase nula. Em outras palavras, poucas freiras são taxadas de negligentes, pelo menos individualmente, no cumprimento de suas obrigações e quanto aos padrões de conduta delas esperados. Suas atitudes nunca são descritas de forma degradante. Os raros casos em que aparecem exemplos de desvios são normalmente utilizados como recurso retórico para reafirmar um posterior retorno à obediência regral e à forma de comportamento desejada. A ausência de menção a vícios e erros das irmãs é mesmo mais acentuada que em textos de natureza semelhante, também versando sobre modelos de vida religiosa, que se referem a casas monásticas franciscanas masculinas. A comparação das obras estudadas neste trabalho com a crônica da província franciscana de Santa Maria da Arrabida, de Joseph de Jesus Maria, ilustra esta diferença. As biografias de religiosos desta província fazem referência às tentações carnais de alguns dos biografados, em parte decorrentes de encontros fora do mosteiro, ${ }^{15}$ um assunto inteiramente ausente nos livros aqui enfocados.

Desvios em relação a um comportamento modelar aparecem, nas obras estudadas, de forma indireta, em especial nos textos de aconselhamento e de prescrição das práticas conventuais cotidianas. Estes, ao recomendarem exercícios para evitar que se desvanecesse o fervor inicial e para que a virtude prevalecesse sobre as "inclinações naturais", e ao apresentarem fórmulas para o exame de consciência que precedia a confissão, acabam indicando condutas desviantes, tidas como contrárias aos ideais de vida santa, mas que não obstante ocorriam nos conventos. Tais condutas são, em geral, exploradas aqui em paralelo aos modelos de virtude correspondentes. Preliminarmente, vale apontar os pecados nunca referidos nas crônicas, mas que aparecem nos temas sugeridos

\footnotetext{
${ }^{15}$ JESUS MARIA, Joseph de. Espelho de penitentes, e chronica de santa Maria da Arabida em que se manifestam as vidas de muntos santos varoens de abalizadas virtudes, e outros que pella verdade da Fé sacrificàraõ as vidas destribuidas por todos os dias do anno. Lisboa Occidental: Officina de Joseph Antonio da Sylva, Impressor da Academia Real, 1737, p. 107-108 e 181.
} 
para o exame de consciência, a exemplo dos pecados contra a castidade - pensamentos e tentações carnais em relação às demais irmãs e a pessoas fora do convento, tocamentos de si, orgasmos durante o sono - atribuídos à incapacidade momentânea de resistir aos apetites naturais. Merecem menção ainda os chamados pecados contra o próximo, como a falta de caridade e compaixão, o escárnio e a detratação, assim como a preferência ou aversão excessivas em relação a certas companheiras de claustro. ${ }^{16}$ Embora este não seja objetivo do presente artigo, estes desvios dão interessantes indicações para uma discussão de aspectos relativos à socialização no interior das casas monásticas.

Entre as práticas e atitudes recorrentes na documentação, uma primeira que merece menção diz respeito à frequência das irmãs nos ofícios divinos e na reza das horas canônicas. Do total de religiosas citadas nas crônicas, 344, somando-se as três, 102 foram lembradas por cumprirem as orações, exercícios espirituais e sacramentos de maneira assídua. Este número (cerca de 30\% do total) inclui as que tinham o costume de passar o dia em oração, mesmo durante a realização de outras tarefas. De fato, o terceiro capítulo da Forma de vida de santa Clara e das constituições coletinas, assim como o capítulo VI da Segunda regra, obrigam todas as religiosas a participarem dessas liturgias, ressaltando a importância da preparação mental e mesmo do gestual adequado para isto. No Ramalhete de flores espirituaes, o coro é referido como o "lugar de vosso principal exercicio", ${ }^{17}$ sendo a obra como um todo centralmente dedicada à exposição e comentário de exercícios espirituais e orações.

Em grande medida, a reforma de santa Colette ampliou as orientações originais dos escritos clarianos sobre a frequência com que as liturgias católicas deveriam ser observadas. Os exemplos mais notórios dizem respeito à confissão e à comunhão. Pela regra da santa de Assis, as clarissas estavam obrigadas a se confessar pelo menos doze vezes ao ano. A comunhão teria que ser feita pelo menos sete vezes, em datas especiais: no natal, na quinta-feira santa, na páscoa, no dia de pentecostes, na assunção de Nossa Senhora, no dia de S. Francisco e no dia de todos os santos. A reforma coletina introduziu a necessidade de confessar e comungar duas vezes por semana, além das sete obrigatórias contidas na regra original. ${ }^{18}$ As constituições coletinas também acrescentaram uma outra novidade

\footnotetext{
${ }^{16}$ SEPULCRO. Ramalhete [...], op. cit., p. 295-303; 281-292, respectivamente.

${ }^{17}$ SEPULCRO. Ramalhete [...], op. cit., p. 32.

${ }^{18}$ St. Clare and her order. Londres: Mills \& Boon, 1912, p. 89.
} 
ao monumento regral clariano, qual seja, a descrição pormenorizada de uma série de orações que teriam lugar em datas especiais. Em verdade, boa parte delas é dedicada a definir como seriam esses rituais, e o nível de detalhamento chega ao ponto de orientar a disposição dos corpos e espíritos.

Uma das evidências do realce dado à frequência nas orações é a existência de dezoito oratórios no Convento da Madre de Deos, em Xabregas, "afora o Antecoro, e a capella da Enfermaria, e a do dormitório”. Este número, aparentemente alto, é justificado pelo fato de que "nem sempre huã Freira pode estar no Coro, porque naõ he lugar em que se possa dar hum suspiro mais alto, nem rezar por contas". ${ }^{19}$ A construção de numerosos locais de veneração dentro de um mesmo monastério pode ter constituído a maneira encontrada para se adequar uma forma de expressão de fé mais performática a uma regra ciosa da uniformidade e do rigor com que cada liturgia deveria ser realizada. A atividade no coro, que deveria ser pautada por um respeito extremo ao protocolo, não era lugar de manifestações individuais de louvor, as quais, no entanto, dada sua relevância na concepção local de religiosidade, não teriam deixado de ser praticadas.

Em adição a este indício de uma apropriação do regulamento fundada em crenças e hábitos locais, o zelo em procurar evitar faltas cometidas no momento do ofício e da oração sugere que tais desvios deviam ser bastante comuns. Maria Madalena do Sepulcro, nas recomendações que faz quanto aos temas a serem explorados no exame de consciência, refere-se primeiramente à falta de atenção e devoção no ofício divino, à presença neste e nas orações em geral unicamente por obrigação, com a irmã desejando ocupar-se de "cousas exteriores". ${ }^{20}$ No livro como um todo, faz recorrente menção às distrações e "pensamentos contrarios" no coro, ao sono no momento da oração mental, à tentação de atender às necessidades do corpo, ficando "froxo para as cousas de Deos", tópicos que também se encontram na seção que trata das rotinas monásticas no Convento de Jesus, em Setúbal. ${ }^{21}$ A própria regra de santa Colette, no seu capítulo III, recomenda que a assistência ao ofício divino deveria ser feita "sem riso, murmúrio ou discurso vão, e sem olhares curiosos e vagos". ${ }^{22}$

\footnotetext{
${ }^{19}$ SACRAMENTO. Notícia [...], op. cit., fl. 105v-106.

${ }^{20}$ SEPULCRO. Ramalhete [...], op. cit., p. 274-280.

${ }^{21}$ SEPULCRO. Ramalhete [...], op. cit., p. 15, 25-27, 35, 68; SÃO JOÃO. Tratado [...], op. cit., fl. $89 \mathrm{v}-92 ; 133-133 \mathrm{v}$.

${ }^{22}$ St. Clare and her order, op. cit., p. 85.
} 
Outro grupo de virtudes que aparece com frequência nas fontes é o conjunto obediência-humildade-mansidão-paciência, mencionado em relação a $28 \%$ das religiosas. Estas virtudes são de fato tratadas com especial destaque, tanto na Forma de vida de santa Clara, quanto na regra promulgada pelo papa Urbano IV. $\mathrm{Na}$ formulação do frei Joseph de Jesus Maria, em sua exposição comentada da Segunda regra, conforme são Tomás de Aquino, o voto de obediência é "primeiro na ordem, e primeiro na excelencia $[. .$.$] porque por elle se consagra a vontade$ a Deos, que he a potencia mais nobre entre as putencias da alma". ${ }^{23}$ Adequarse a ele devia constituir uma das maiores dificuldades enfrentadas quando do ingresso no convento, num universo em que aproximadamente $38 \%$ das monjas eram oriundas de famílias pertencentes às elites políticas e econômicas do reino, $26 \%$ ocuparam cargos de prestígio nos mosteiros e outras exerceram liderança por seus prodígios. Talvez por isto a insistência, na literatura de aconselhamento, nas práticas de humildade, a exemplo de atender sem questionamento às correções da mestra ou outras superiores, postar-se no chão e outras formas de auto-humilhação, abaixando-se "até o profundo abismo do [seu] nada". ${ }^{24}$

Mesmo atos motivados por um desejo de maior perfeição podiam ser tidos como quebra da obediência. $\mathrm{O}$ conflito entre estas duas interpretações pode ser observado no livro do frei Francisco da Annunciação († 1720), cujo tema central é a licitude de certas clarissas, com licença do seu prelado, adotarem hábito de pano mais vil que as demais no seu convento. No entanto, ainda que considere a possibilidade de que as diferenças quanto ao tipo e à cor de tecido dos hábitos nos conventos de Santa Clara pudessem constituir desrespeito ao voto de obediência, o autor conclui que, desde que não tivessem recebido orientação contrária do arcebispo, as freiras que vestissem panos grosseiros estariam praticando uma ação virtuosa e não pecando. ${ }^{25}$

$\mathrm{O}$ respeito ao silêncio e o isolamento do mundo constituem um outro conjunto de características valorizadas no modelo de comportamento das clarissas. Das religiosas mencionadas nas crônicas, cerca de 13\% são apontadas como especialmente obedientes a estes princípios. A clausura, entendida em seu sentido extenso, não se reporta apenas ao recolhimento intramuros, mas supõe

\footnotetext{
${ }^{23}$ JESUS MARIA, Joseph. Espelho de perfeytas religiosas, exposição da Segunda regra de s. Clara [...]. Porto: Officina de Manoel Pedroso Coimbra, 1743, p. 47-48.

${ }^{24}$ SEPULCRO. Ramalhete [...], op. cit., p. 108. Ver também p. 64-74.

${ }^{25}$ ANNUNCIAÇÃO, Francisco da. Consulta mystico-moral sobre o habito de certas religiosas da Ordem de S. Clara Urbanas [...]. Coimbra: Real Collegio das Artes da Companhia de Jesus, 1717.
} 
também um afastamento de todos os tipos de atrações mundanas. Dentro do ambiente claustral, isto redundava em atitudes que visassem evitar conversas desnecessárias e o interesse por assuntos que fugissem das obrigações de vida das sórores. O capítulo IX da Primeira regra e o XIX da Segunda dispõem que, na medida do possível, mesmo as irmãs que serviam fora do mosteiro deveriam cumprir estes preceitos. Estas, além disso, estavam proibidas de, ao regressarem à casa, falarem às irmãs "de assuntos inúteis e mundanos que possam ser causa de relaxamento e dissipação". As crônicas coletinas dão numerosos exemplos que aludem à importância desta matéria entre as religiosas. Um trecho do primeiro diálogo da Notícia é expressivo quanto à necessidade da manutenção do silêncio e do isolamento penitencial. Uma das participantes conta ter deixado de encontrar um irmão com quem já não falava havia muitos anos e que estava para embarcar para a Índia, numa viagem em que acabou falecendo, por ser já quaresma, quando ele chegou em Lisboa. ${ }^{26}$ Já o Tratado oferece um exemplo de obediência mais extrema ao silêncio. A madre Catherina de Iesu, biografada na crônica, além de gastar "muitas horas" no coro aos pés de um crucifixo e manter "com excesso" o jejum e as demais abstinências, guardava perpétuo silêncio. Mesmo sendo "grande latina, legista e escrivam habel para o Choro", a irmã se resumia a falar poucas palavras e ainda assim somente nas ocasiões "mui necessarias". ${ }^{27}$ Maria Benta do Ceo conta que seis religiosas do Convento de Nossa Senhora da Conceição em Braga - Maria Josefa de Jesus e suas seguidoras - tomaram a decisão de permanentemente guardar silêncio, só quebrado quando falavam aos confessores e a seus irmãos. ${ }^{28}$

Embora alerte para o cuidado especial que as irmãs deveriam ter com relação aos contatos com pessoas de fora do convento, para que "naõ tragaõ o máo ar, que [causa] as infermidades da alma, de que ainda vos naõ achais bem convalecida[s]", e endosse as disposições da regra quanto ao silêncio, Maria Madalena do Sepulcro parecer reputar a conversação necessária. Ela recomenda que as religiosas conversassem quando lhes fosse permitido, "porque os bemaventurados em o Ceo não interrompem nunca a sua conversaçaõ com Deos, porém nós outras naõ somos capazes desta continua elevaçaõ de espirito". ${ }^{29}$

\footnotetext{
${ }^{26}$ SACRAMENTO. Notícia [...], op. cit., fl. 25v.

${ }^{27}$ SÃO JOÃO. Tratado [...], op. cit., fl. 202v.

${ }^{28}$ CEO. Jardim do сео [...], op. cit., p. 96 e 100.

${ }^{29}$ SEPULCRO. Ramalhete [...], op. cit., p. 74-76.
} 
Quanto a este aspecto, se observa, uma vez mais, a tensão entre necessidades e fraquezas cotidianas e a conduta considerada modelar.

Um percentual de incidência superior a todos os acima mencionados, nas biografias de religiosas nas crônicas, é o relativo à prática de penitências, jejuns e mortificações, qualificativo de cerca de $32 \%$ das freiras citadas. E aqui emerge um outro elemento que ilumina formas particulares de apropriação, por elas, do que é disposto nos regulamentos. Estes de fato advertem sobre as "asperezas e austeridades" que as que tomassem o hábito seriam obrigadas a observar, incluindo contínuo jejum e privações. Os rigores da vida conventual são inclusive a razão apontada para a recusa de admissão daquelas que "pela idade, doença ou fraqueza de espírito, se mostr[assem] incapaz[es] para este gênero de vida". Contudo, as mortificações e os castigos relatados nas crônicas, que teriam sido recebidos pelas monjas ou infligidos por elas mesmas a seus corpos, parecem ultrapassar o espírito de penitência sugerido nas regras.

De acordo com a madre Leonor de São João, as noviças do Convento de Jesus de Setúbal eram acostumadas, desde cedo, a dizerem suas culpas todos os dias para a mestra da escola. Eram, então, repreendidas e castigadas por "qualquer desfalecimento geral ou particular" que tivessem cometido, tendo-se "por mui grave mui pequena falta". O castigo físico não se restringia às ocasiões em que as noviças e recém-professas cometiam faltas ou se desviavam das orientações de suas mestras. Ainda segundo o Tratado, os castigos eram aplicados regularmente: "he costume açoutar a mestra as discipulas nas segundas, quartas e sextas". E com "5 varas de marmeleiro bem juntas a todas se daõ os açoutes ordinários assim na escola como na comunidade". Segundo o relato, as noviças e professas na escola tinham ainda que passar por uma série de humilhações, tal como comerem no chão do refeitório e beijar os pés das que comiam sentadas à mesa. Nas segundas-feiras, elas se prostravam no chão para que as demais freiras, quando adentrassem no refeitório, pisassem sobre elas. ${ }^{30}$

O Tratado e a Notícia também registram a criação de pequenos grupos de freiras que se penitenciavam coletivamente. Em Xabregas, essas atividades foram encabeçadas pela sóror Constança de Jesus e pela madre Colecta, a primeira abadessa da casa. Aquela, "por devoçaõ sua se mandava disciplinar em as costas por huã Religioza de quem se fiava [...] a quem pedia que o fizesse com grande força”. Já a madre Colecta "uzava desse exercicio, e em huã quaresma

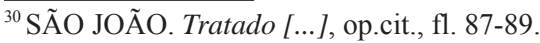


se determinou em tomar sinco mil e tantos açoutes, como foram os de nosso Senhor Jesus Christo". O hábito de "se ajudarem as outras em o caminho da perfeiçaõ", é apontado como comum no Convento da Madre de Deus. Eram repreendidas as faltas de que a comunidade tinha notícia e, "se eraõ occultas, descubriaõ-nas, para deste modo terem mortificaçaõ". Outro trecho da mesma crônica sintetiza a importância das penitências na espiritualidade praticada na casa, afirmando que "sem mortificação não há virtude". ${ }^{31}$

No caso setubalense, a liderança do grupo de penitências mútuas ficou a cargo de Maria da Trindade que, além de fazer cilícios tão ásperos que era impossível esconder seus sangramentos, ainda carregava uma pedra na boca "por naõ fallar palavra fora do necesario". Esta madre, após o término do período de dois anos, de frequência regular à escola, acordou com suas companheiras "para em secreto [...] exercitarem [as penitências da escola], o que faziaõ de noite em lugar escuro dizendo as culpas a huma dellas que como Mestra as reprehendia asperamente". ${ }^{32}$

Nas biografias do Jardim do ceo, a prática de rigores e flagelos pelas irmãs é mencionada de forma constante. Disciplinas de ferro, cilícios de ferro pelo corpo, o uso de roupas de tecido áspero e de uma tábua como cama, os jejuns e as abstinências aparecem recorrentemente nos relatos. Aqui também se observam os extremos como os de Isabel Maria da Conceição que rasgou duas vezes o peito com um canivete "para escrever com o sangue do coração huma protestação a seu Divino Esposo", ficando-lhe a ferida aberta por toda a vida; e os de Maria Josefa de Jesus que cobria a pele com urtigas e se deitava no chão à porta do coro, para que as demais pisassem nela. ${ }^{33}$ Uma madre do convento de Setúbal também teria pedido, na hora de sua morte, para ter seu corpo pisoteado por toda a comunidade; e outra, de tanto que derramava sangue, "apodreciam-lhes as carnes". ${ }^{34}$

No que diz respeito às penitências e mortificações, os textos de aconselhamento convergem com as crônicas na ênfase dada a estas práticas. No Ramalhete deflores espirituais são abundantes as referências a elas, as quais, conforme o prescrito neste e nos demais textos, deveriam se espelhar no sofrimento de Cristo na paixão. Sua autora recomenda às irmãs que acrescentassem, por sua própria

\footnotetext{
${ }^{31}$ SACRAMENTO. Notícia [...], op.cit., fl. 82v-83 e 100, respectivamente.

${ }^{32}$ SÃO JOÃO. Tratado [...], op. cit., fl. 189v-190.

${ }^{33}$ CEO. Jardim do сео [...], op. cit., p. 162-163 e 107, respectivamente.

${ }^{34}$ SÃO JOÃO. Tratado [...], op. cit., fol. 212-212v e 223v, respectivamente.
} 
conta, penitências às recebidas do confessor. Estas, assim como as mortificações, são consideradas uma forma de expiar e de evitar a condição de pecador. ${ }^{35}$

O Espelho de perfeytas religiosas também ressalta a importância das penas, suplícios e práticas similares. Conforme apontado anteriormente, o livro é uma apresentação da Segunda regra de santa Clara, com comentários do autor e outros adendos. Na primeira parte da obra, há uma versão em português da regra, cujo conteúdo não difere do de outras versões ou do conteúdo do original latino. É nos comentários e adendos que se observa o que parecem ser evidências de uma adaptação, não necessariamente intencional, do regulamento ao contexto português do Antigo Regime. Na seção que versa sobre ações cotidianas que a religiosa que desejasse ser perfeita deveria praticar, o frei recomenda que

Nas mortificaçoens que fizer, ou sejaõ as disciplinas da Communidade, ou as particulares de cilicios, jejuns, \&c. naõ as faça materialmente sem consideraçaõ, mas lembrese dos jejuns de Christo no dezerto, dos açoutes que lhe deraõ, das asperas cordas com que o ataraõ, e coroa de espinhos, que lhe puzeraõ, para nas acçoens que faz de mortificaçaõ o acompanhar nas suas penas, e merecer o perdaõ das suas culpas, castigando na carne as suas rebeldias. ${ }^{36}$

Noutra passagem, ao discutir os três caminhos "por onde se sobe à perfeiçaõ", o frei aponta que se conhece estar a alma na via unitiva, "a dos perfeitos", "quando naõ sô dezeja as occazioens de padecer por amor de Deos, mas as busca, e dezeja ser desprezado (sic), e abatido (sic) de todos, alegrando-se com os desprezos, e vilipendios". ${ }^{37}$

Muitas vezes, os excessos de flagelos resultavam em graves enfermidades. Estas, aliás, causadas por penitências ou não, eram consideradas como manifestações de virtude das biografadas. Cerca de $24 \%$ das religiosas mencionadas nas crônicas apresentaram algum tipo de doença. Destas, 9\% teriam demonstrado paciência excepcional ao enfrentar dores, febres, entrevamentos, frenesis, cegueiras e outros sintomas variados.

A interpretação particular, pelas monjas, das regras relativas às privações corporais e mortificações, que foram amplificadas na prática no interior dos

\footnotetext{
${ }^{35}$ SEPULCRO. Ramalhete [...], op. cit., p. 21-23, 96 e passim.

${ }^{36}$ SEPULCRO. Ramalhete [...], op. cit.., p. 201.

${ }^{37}$ SEPULCRO. Ramalhete [...], op. cit., p. 232.
} 
conventos, pode estar associada à relevância do ascetismo no ethos religioso da Reforma Católica. De acordo com José Sebastião da Silva Dias, que discute o fenômeno no que diz respeito à espiritualidade em Portugal, esta relevância se expressa na austeridade, nas penitências e no papel central dos mistérios e das devoções da paixão na piedade cristã da época. Dias afirma ainda que, desde 1553, quando de sua publicação em Portugal, os ensinamentos de Inácio de Loiola nos Exercícios espirituais tiveram importante papel na reorientação de círculos devotos lusos, inclusive conventos femininos do ramo franciscano, afastando-os da via mística e aproximando-os do ascetismo, um processo que precedeu a influência que vieram a ter as ideias de santa Teresa e são João da Cruz. ${ }^{38} \mathrm{Na}$ Europa dos séculos XVII e XVIII como um todo, observa-se uma ênfase no sofrimento como componente do amor cristão. Tal ênfase estava vinculada à devoção às cinco chagas de Cristo e à sua paixão, parte do que Louis Châtellier chama de "uma religião da cruz", que se difundiu por terras europeias no período. ${ }^{39} \mathrm{E}$ ainda relevante considerar aqui o influxo das constituições publicadas pelos visitadores Juan Daza e fr. Miguel Fenals, na Espanha, mais de um século antes (em 1495), que instituíram a reforma dos conventos urbanistas. Entre as determinações das suas dezessete "obrigações fundamentais", encontrase o estabelecimento de um "regime de culpas", mediante o qual as religiosas deveriam expiar seus pecados e penitenciar-se publicamente. ${ }^{40}$ Imersas num meio em que práticas ascéticas e penitências eram grandemente valorizadas, as irmãs teriam dado a elas ênfase maior do que a prevista nos regulamentos.

Em verdade, as práticas referidas nos escritos conventuais femininos portugueses extrapolam os ideais ascéticos canônicos. Mesmo no estágio preliminar do embate do cristão contra tudo que se opõe à virtude e à perfeição, de acordo com são Tomás de Aquino, estágio daqueles que estão iniciando a via espiritual e necessitam de um esforço maior de purificação e reforma - a "via purgativa", em que a prática principal é a mortificação dos sentidos exteriores e interiores -, os meios centralmente previstos no sentido de alcançar a perfeição são a

\footnotetext{
${ }^{38}$ SILVA DIAS, José Sebastião da. Correntes do sentimento religioso em Portugal (séculos XVI a XVIII]. Coimbra: Universidade de Coimbra, 1960, 2 vols., p. 449-451; 651-652.

${ }^{39}$ CHÂTELLIER, Louis. A religião dos pobres: As missões rurais na Europa e a formação do catolicismo moderno, séc. XVI-XIX. Lisboa: Editorial Estampa, 1995, p. 140-153.

${ }^{40}$ SOUZA. Rainha d. Leonor, op. cit., p. 518.
} 
oração, a leitura espiritual, a meditação e a frequência aos sacramentos. Nada é dito a propósito de rigores excessivos e suplícios. ${ }^{41}$

A paixão de Cristo aparece, nos diversos gêneros de texto analisados neste artigo, como o mais importante objeto de devoção. Numerosas passagens do Ramalhete de flores espirituais fazem referência às religiosas como "filhas da Payxão", exortando-as a, seguindo o modelo do salvador, estarem "crucificada[s] com elle". O poema de Cecilia do Espirito Santo tematiza os diferentes passos e detalhes da paixão, muitas vezes evidenciando as conotações eróticas da relação das sórores com o corpo de Cristo. Do poema também emerge a ideia das mortificações e sofrimento como imitação a Cristo, a exemplo dos versos "Sois do amor lindo modello, / E nas azas desse amor / Muitas penas considero". ${ }^{42}$ Esta "atitude de co-paixão" é observada, por Isabel Morujão, em diversos autores e autoras de poesia religiosa portuguesa dos séculos XVII e XVIII. ${ }^{43}$

O que emerge dos textos é, em verdade, a coexistência entre ascetismo e a via mística. Tal coexistência está de acordo com a tendência da piedade franciscana a promover a combinação entre ambos, vista com ressalvas pelos defensores de uma ascética humanista positiva que recusava a elevação aos estados místicos e a supervalorização das observâncias exteriores. ${ }^{44}$ Tal combinação ocorreu também entre outras ordens e grupos de religiosos. No século XVIII, os jacobeus, oriundos de diversas congregações, eram ascetas e místicos. ${ }^{45}$

É significativo o número de religiosas apontadas como tendo protagonizado fenômenos extraordinários em vida $(18,3 \%)$ ou a quem foram associadas manifestações desta natureza após a morte $(6,4 \%)$. Dentre estas últimas, as mais frequentes se referem à não deterioração de seus corpos - que teriam permanecido flexíveis e rejuvenescidos em formosura -, a milagres operados, à exalação de odor agradável - o conhecido "odor de santidade" - e à emissão de luzes. O caso de Custodia Maria do Sacramento, no Convento da Conceição

\footnotetext{
${ }^{41}$ VACANT, A., MANGENOT, E. e AMANN, E.. Dictionnaire de théologie catholique. Paris: Librairie Letouzey et Ané, 1923, tomo I, p. 2037-2050.

${ }^{42}$ ESPIRITO SANTO. Colloquios [...], op. cit, s/p.

${ }^{43}$ MORUJÃO. Por trás da grade, op. cit., p. 531-543.

${ }^{44}$ SILVA DIAS. Correntes do sentimento religioso [...], op. cit., p. 152-154 e 298; PIEDADE, Antonio da. Espelho de penitentes, e chronica da Provincia de Santa Maria da Arrabida da regular, e mais estreita observancia da Ordem do Serafico Patriarca S. Francisco, no Instituto Capucho. Tomo I, Lisboa: Joseph Antonio da Sylva, Impressor da Academia Real, 1728; JESUS MARIA. Espelho de penitentes [...], op. cit., passim.

${ }^{45}$ SALES SOUZA, Evergton. Jansénisme et réforme de l'Église dans l'Empire portugais - 1640 à 1790. Paris: Fundação Calouste Gulbenkian, 2004, p. 187-234.
} 
de Braga, serve de ilustração. De acordo com o relato de Maria Benta do Ceo, após seu falecimento, Custodia teria ficado com aparência de viva, com o corpo flexível e o sangue líquido. Três dias após sua morte, seu corpo não mostrava sinais de deterioração e exalava um cheiro muito agradável. Logo teria começado a fazer milagres, operados através do contato com relíquias feitas com seu sangue, pedaços do hábito e outros objetos de uso pessoal. Estes incluíam a cura de diversas doenças e até mesmo fazer chover, em resposta a pedido da comunidade. Sinais, ainda quando era viva, de que se tratava de uma santa (um raio de luz que teria aparecido sobre a sua cela) teriam sido então lembrados pelas outras freiras. O Jardim do ceo registra com algum detalhe cinquenta e um milagres de Custodia, em parte atestados por membros do clero. Seus atos de piedade e o estado do seu corpo após a morte foram também certificados pelo confessor, pelo notário geral, por um médico, um sangrador e um cirurgião, autoridades das diferentes instituições cujo endosso poderia conferir fidedignidade e relevância aos fatos. ${ }^{46}$

Quanto aos fenômenos experimentados em vida pelas religiosas citadas, os mais comuns são contatos com manifestações divinas, tais como a audição de músicas celestiais, a visualização de anjos ou cordeiros sagrados e conversas com santos ou com Deus, as quais, em conjunto, teriam sido protagonizadas por $9,3 \%$ das biografadas. Um número ainda maior (10,2\%) teria manifestado o dom de lágrimas e em torno de 5\% teriam experimentado êxtases e "elevações".

A menção a fenômenos extáticos e visões em vida, e a acontecimentos extraordinários após a morte, também remete ao problema da apropriação, pelas monjas, das prescrições clarianas quanto a um modelo de vida santa. Não há, nas regras e escritos de santa Clara, referência a fenômenos extraordinários. As clarissas portuguesas parecem ter compreendido a proposta da fundadora da ordem de acordo com um contexto em que tais ocorrências eram comuns. Diferentes fontes do período, incluindo processos inquisitoriais, tratados sobre assuntos de caráter devocional e registros sobre vida conventual, indicam que milagres, êxtases e encontros com o que era percebido como Deus ou alguma realidade última eram tidos como comuns na época, em especial no interior das casas monásticas femininas, mas também em mosteiros capuchos masculinos e conventos de outras ordens religiosas. Ao que parece, membros das diferentes

$\overline{{ }^{46} \text { CEO. Jardim do ceo }}[. .$.$] , op. cit., p. 39-78.$ 
instâncias da hierarquia eclesiástica compartilhavam a crença na veracidade dos fenômenos e os tinham como indício de virtude e santidade. ${ }^{47}$

Entre as fontes que apresentam indicações da importância de ocorrências extraordinárias na cultura religiosa do período encontra-se o Espelho de perfeytas religiosas, do frei Joseph de Jesus Maria, um autor com formação em teologia moral e qualificador do Santo Ofício. A obra traz, no final, uma "Explicaçaõ de alguns termos mais communs da Theologia Mistica". Vários entre os termos para os quais o clérigo apresenta uma breve definição remetem ao êxtase, a visões e a outras formas de transformação do espírito mediante processo extraordinário. ${ }^{48}$

O modo como Joseph de Jesus Maria trata tanto a ocorrência de fenômenos extraordinários quanto o rigor das penitências e mortificações o aproxima mais de uma cultura religiosa partilhada pelas clarissas portuguesas, do que da abordagem a estas práticas que emerge das regras. Neste sentido, sua obra pode ser considerada como um elemento de mediação e adaptação dos regulamentos clarianos ao universo religioso local.

Por fim, parece ainda ter havido adaptações, nos conventos estudados, quanto à ênfase na simplicidade característica dos regulamentos franciscanos. É certo que a Segunda regra de santa Clara, promulgada por Urbano IV, prevê, no seu capítulo XXI, que as irmãs podiam "receber, possuir e reter em comum rendas e possessões". As reformas dos conventos femininos em Portugal nos começos da época moderna, embora tenham sido promovidas sob a égide dos observantes, não romperam com a tradição urbanística, uma aparente contradição que se explica, em parte, pela difusão da política defendida pelo cardeal Cisneros. $\mathrm{O}$ cardeal, que teve papel preponderante na reforma franciscana em território espanhol, não considerava conveniente privar as clarissas de rendimentos e bens de raiz, tendo ordenado inclusive a transferência de patrimônios de conventos franciscanos masculinos para os femininos, à medida que os reformava. ${ }^{49}$

\footnotetext{
${ }^{47}$ SILVA DIAS. Correntes do sentimento religioso [...], op. cit., p. 152-154; BELLINI, Lígia. Penas, e glorias, pezar, e prazer: espiritualidade e vida monástica feminina em Portugal no Antigo Regime. In: BELLINI, Lígia, SALES SOUZA, Evergton e SAMPAIO, Gabriela dos Reis (org.). Formas de crer. Ensaios de história religiosa do mundo luso-afro-brasileiro, séculos XIV - XXI. Salvador: EDUFBA; Corrupio, p. 81-105, p. 97-103; e Cultura religiosa e heresia em Portugal no Antigo Regime: notas para uma interpretação do molinosismo. In: Estudos ibero-americanos. Porto Alegre: PUC, vol. XXXII, n 2, dezembro 2006, p. 187-203, passim.

${ }^{48}$ JESUS MARIA. Espelho de perfeytas religiosas, op. cit., p. 250-252.

${ }^{49}$ SOUZA. Rainha d. Leonor, op. cit., p. 456.
} 
Mas as descrições dos bens e do modo de vida nos monastérios clarianos portugueses sugerem que estes por vezes ultrapassavam o que estava previsto nos regulamentos. As instalações das concepcionistas no Convento de Braga são descritas como um "magnifico, e sumptuoso edificio". Maria Benta do Ceo faz referência a outros bens da casa, qualificada como "opulenta" - "vinte e seis moradas de casas sobradadas" e terras, além de doações anuais e rendas $-{ }^{50}$ e ao fato de que certas freiras mantinham bens pessoais. A biografia de dona Jeronyma Francisca de Christo relata a perda de seus bens em incêndio ocorrido na casa em 1761, afirmando ser ela "das mais ricas, que havia no Convento". ${ }^{1}$

As crônicas do Convento de Jesus de Setúbal e da Madre de Deus em Xabregas documentam a estreita relação destas casas com o poder monárquico e os benefícios - inclusive econômicos - que disto resultavam. Alvarás régios garantiam, para estes monastérios, privilégios como a isenção do pagamento de certos tributos. Ao mesmo tempo em que reduzia os gastos dos erários conventuais, a intercessão do soberano podia aumentá-los significativamente, por exemplo aumentando a atração dos fiéis para estas casas e, com eles, o recebimento de esmolas e doações as mais diversas. ${ }^{52}$ Além disso, era o poder régio que também determinava a amplitude da atuação dos procuradores e mamposteiros dos conventos. Estes tinham papel central na arrecadação de doações vez que, munidos da autorização necessária, podiam realizar seu trabalho em diversas vilas para além da localidade original da comunidade. Como resultado dos favores da corte, os primeiros edifícios do Convento de Setúbal foram construídos de acordo com o projeto e sob a supervisão de Diogo Boitac, arquiteto que havia se transferido da Itália para Portugal a convite do rei d. João II (cujo reinado se estendeu de 1482 a 1495) e que foi um dos principais expoentes do estilo chamado manoelino. O Tratado e a Notícia indicam uma presença expressiva de imagens e de retábulos de grande valor artístico, doados pela família real, dispostos nos mosteiros cuja memória se propõem registrar. ${ }^{53}$ É bem verdade que a crônica sobre Setúbal relata que todos os que visitavam as acomodações das religiosas ficavam "mui edificados da simpleza das barras, pobreza das camas e estreiteza do lugar”. Mas, a par dos bens referidos acima, também faz referência

\footnotetext{
${ }^{50}$ CEO. Jardim do ceo [...], op. cit., p. 24, 27 e 33.

${ }^{51}$ CEO. Jardim do сео [...], op. cit., p. 161.

${ }^{52}$ SOUZA. Rainha d. Leonor, op. cit., p. 493; SÃO JOÃO. Tratado [...], op. cit., fl. 58.

${ }^{53}$ SÃO JOÃO. Tratado [...], op. cit., fl. 173v-179; SACRAMENTO. Notícia [...], op. cit., fl. $17 \mathrm{v}-18$.
} 
à existência de servos que trabalhavam na horta, na cozinha, na lavagem de roupas e outros serviços. Eram incluídos, nas próprias orações, pedidos "pello aumento [dos] bens espirituaes e temporaes [do] convento". ${ }^{54}$ A opulência nos mosteiros clarianos estudados talvez se explique em parte pelo fato de que, como foi dito anteriormente, parcela considerável das irmãs cuja existência foi registrada era oriunda de famílias nobres ou ligadas à administração central.

Tendo em conta que praticamente transcorreu um século entre a composição de duas das crônicas conventuais analisadas neste trabalho e a elaboração da terceira delas, procurou-se comparar as informações sobre crenças e práticas veiculadas nestes tratados em ambos os séculos, com o objetivo de investigar mudanças e permanências. Esta investigação se nos afigurou como ainda mais pertinente em vista das importantes transformações nos modos de pensar e nos mores ocorridas em Portugal e na Europa como um todo, no período. Portugal passa da subordinação à Espanha até 1640 para a consolidação das instituições e rituais associados à corte no século XVIII. Firmam-se as normas de civilidade cortesã e acentua-se a preocupação com a imagem projetada socialmente. Florescem, em terras portuguesas, o humanismo formal da chamada segunda escolástica e o iluminismo católico, voltado para a instituição de um saber enciclopedista. De acordo com o projeto racionalista da ilustração, ocorrem inovações nos diferentes âmbitos culturais. ${ }^{55}$ Especificamente no plano religioso, assiste-se, no século XVIII, à implementação dos resultados maduros do Concílio de Trento, com uma maior preocupação com a formação do clero e a fundação de seminários diocesanos. Renova-se, na época, o movimento missionário na Europa e, como foi visto anteriormente, instituem-se novas devoções. ${ }^{56}$

Em que pesem estas transformações, o resultado das comparações feitas entre os dados da documentação quanto aos ideais de vida religiosa foi um quadro em que predomina a permanência. Constituem ilustração disto os percentuais de monjas que teriam protagonizado fenômenos extraordinários em vida ou após a morte, $30 \%$ nos textos do século XVII e cerca de $41 \%$ no do XVIII. O percentual de irmãs que teriam se destacado pela frequência nas orações varia de $32 \%$ para $23 \%$, respectivamente. A prática de penitências e mortificações

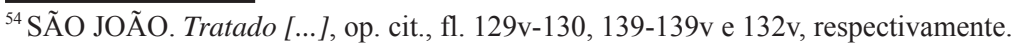

${ }^{55}$ GOUVEIA, António Camões. Estratégias de interiorização da disciplina. In: HESPANHA, António Manuel (coord.). História de Portugal (vol. 4). O Antigo Regime (1620-1807). Lisboa: Editorial Estampa, 1992, p. 415-449.

${ }^{56}$ CHÂTELLIER. A religião dos pobres, op. cit., parte II.
} 
oscila de $33 \%$ para $27 \%$, de um século para outro. Estes resultados sugerem o acerto de se analisar as fontes estudadas em conjunto.

Considerados em sua totalidade, os aspectos discutidos neste artigo estão de acordo com a proposição de Michel de Certeau e Roger Chartier de que as práticas do cotidiano e as formas de consumo cultural devem ser pensadas como táticas produtoras de sentido, modos particulares de utilizar objetos ou normas que circulam na sociedade. Estes são recebidos, compreendidos e manipulados em função da especificidade dos interesses e trajetórias históricas não apenas dos indivíduos e instituições que produzem normas e modelos, mas também dos projetos e visões de mundo daqueles que deles se apropriam. ${ }^{57} \mathrm{O}$ voto de obediência aos princípios franciscanos e às instituições e autoridades eclesiásticas, que recebe ênfase especial na Forma de vida de santa Clara e nas constituições dela derivadas, não implicava forçosamente numa vivência religiosa desvinculada de determinações do universo de crenças e práticas no qual as monjas estavam inseridas.

\section{Referências bibliográficas}

BELLINI, Lígia. Penas, e glorias, pezar, e prazer: espiritualidade e vida monástica feminina em Portugal no Antigo Regime. In: Lígia BELLINI, Evergton SALES SOUZA e Gabriela dos Reis SAMPAIO (org.). Formas de crer. Ensaios de história religiosa do mundo luso-afro-brasileiro, séculos XIV - XXI. Salvador: EDUFBA; Corrupio, p. 81-105.

BELLINI, Lígia. Cultura religiosa e heresia em Portugal no Antigo Regime: notas para uma interpretação do molinosismo. In: Estudos ibero-americanos. Porto Alegre: PUC, vol. XXXII, n² 2, dezembro 2006, p. 187-203.

CHARTIER, Roger. Cultura popular: revisitando um conceito historiográfico. In: Estudos Históricos. Rio de Janeiro, vol. 8, n 16, 1995, p. 179-192.

CHÂTELLIER, Louis. A religião dos pobres. As missões rurais na Europa e a formação do catolicismo moderno, séculos XVI-XIX. Lisboa: Editorial Estampa, 1995.

DHONT, René-Charles. Clare among her sisters. Youngstown, Ohio: Catholic Publishing Company, 1987.

GOUVEIA, António Camões. Estratégias de interiorização da disciplina. In: HESPANHA, António Manuel (coord.). História de Portugal (vol. 4). O Antigo

\footnotetext{
${ }^{57}$ CHARTIER, Roger. Cultura popular: revisitando um conceito historiográfico. Estudos Históricos. Rio de Janeiro, vol. 8, $\mathrm{n}^{\circ}$. 16, 1995, p. 179-192.
} 
Regime (1620-1807). Lisboa: Editorial Estampa, 1992, p. 415-449.

MACHADO, Diogo Barbosa. Biblioteca lusitana histórica, crítica e cronológica. $2^{a}$ ed. Lisboa: Academia Real da História Portuguesa, 1930-1934, 4 vols.

MORUJÃO, Isabel. Entre o convento e a corte: algumas reflexões em torno da obra poética de sóror Tomásia Caetana de Santa Maria. Revista da Faculdade de Letras - Línguas e Literaturas. Porto, Anexo V, 1993, p. 123-141.

MORUJÃO, Isabel. Por trás da grade: Poesia conventual feminina em Portugal (séculos XVII - XVIII). Tese de doutorado. Porto: Universidade do Porto, 2005.

SALES SOUZA, Evergton. Jansénisme et réforme de l'Église dans l'Empire portugais - 1640 à 1790. Paris: Fundação Calouste Gulbenkian, 2004.

SENSI, Mario. Clarisses: entre spirituels et observants. In: Sainte Claire D’Assise et sa postérité - Actes du Colloque International organisé à l'occasion du VIII Centenaire de la naissance de sainte Claire. Paris: Comité du VIII ${ }^{\mathrm{e}}$ Centenaire de sainte Claire, 1995, p. 101-118.

SILVA DIAS, José Sebastião da. Correntes do sentimento religioso em Portugal (séculos XVI a XVIII). Coimbra: Universidade de Coimbra, 1960, 2 vols.

SOUZA, Ivo Carneiro de. Rainha d. Leonor (1458-1525). Poder, misericórdia, religiosidade e espiritualidade no Portugal do Renascimento. Lisboa: Calouste Gulbenkian, 2002.

St. Clare and her order. Londres: Mills \& Boon, 1912.

VACANT, A., MANGENOT, E. e AMANN, E. Dictionnaire de théologie catholique. Paris: Librairie Letouzey et Ané, 1923. 